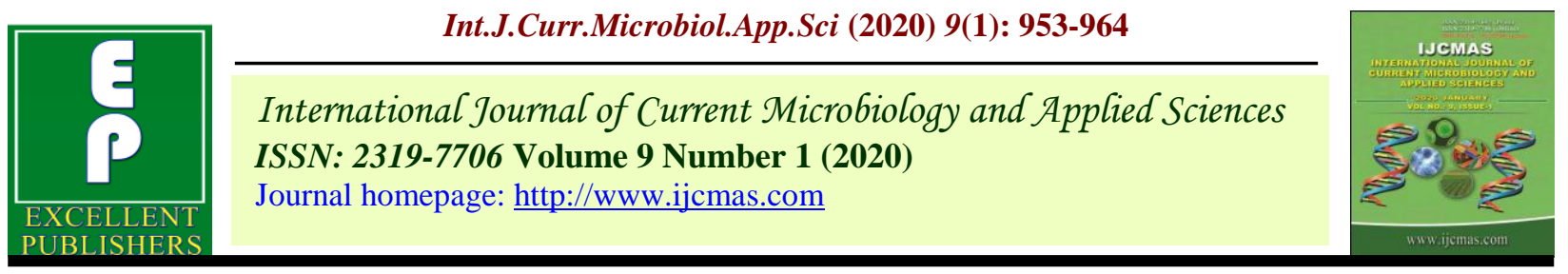

Original Research Article

https://doi.org/10.20546/ijcmas.2020.901.107

\title{
The Micronutrients Status and Physio-Chemical Properties of Geo Referenced Soils of Solapur District in Maharashtra, India
}

\author{
Reshma D. Mulani*, Vijay B. Upadhye and B. D. Bhosale \\ Department of chemistry, Lotus English School and Junior College, Pandharpur, \\ Maharashtra, India \\ *Corresponding author
}

Keywords

Zinc, Iron,

Manganese,

Copper, Nutrient

index, Micro

nutrient, Total

content of soil,

Analysis of soil,

Soil quality and soil

nutrients

Micronutrient, Soil nutrient account

Article Info

Accepted:

15 December 2019

Available Online:

20 January 2020

\section{A B S T R A C T}

The present investigation was carried out for evaluation of the status of DTPA-Fe, $\mathrm{Cu}, \mathrm{Mn}$ and $\mathrm{Zn}$ in relation with chemical properties in soils of Solapur district for this purpose representative soil samples were collected from different villages of Solapur district. The micronutrient and some important soil physico-chemical properties were investigated by using GPS and GIS techniques. Considering the critical limits of soil micronutrients, all soil associations were not adequately supplied with DTPA extractable micronutrients. Irrespective of land use, the DTPA extractable cationic micronutrients were positively related with organic carbon content and negatively related to calcium carbonate content. The DTPA- extractable $\mathrm{Fe}, \mathrm{Zn}, \mathrm{Mn}$ and $\mathrm{Cu}$ were extracted with diethelene tri- amine penta-acetic acid (DTPA) solution (Lindsay and Norwell 1978) and subsequently analysed with the help of atomic absorption spectrophotometer (Chemito203). The soil under the study were neutral to alkaline in reaction, safe in electrical conductivity and moderately calcareous in nature. DTPA-copper was recorded in medium quantity, while DTPA-iron, DTPA-zinc were low quantity and DTPA-manganese was high quantity.

\section{Introduction}

One of the primary concerns of agricultural research in the tropics has been to increase crop production through the efficient use of fertilizers. Micronutrients soil fertility depleted due to continuous cultivation of high yielding crop varieties to meet the increasing food demand of the country. Several field crops have constrained sustainable growth in productivity due to zinc and boron deficiencies. Zinc deficiency was found widespread in Indian soils. Indian agriculture during the past few years has achieved a fourfold growth in food production by adopting modern agricultural practices. 
However, intensive cultivation of high yielding varieties, increased use of NPK fertilizers free from secondary and micronutrients, decreased use of organic manures and lack of crop residue recycling have led to depletion of native nutrient fertility and resulted in widespread deficiencies of secondary and micronutrients. The micronutrients are iron, copper, zinc, manganese, boron which needed to plant in small amount but effect on crop yield. Low natural fertility of soil was main cause of micronutrient deficiency. The suitable fertilization recommendation and to avoid deficiency or toxicity problems of micronutrient, status of micronutrient availability in soil is important. $\mathrm{pH}$, organic carbon, CEC, and available nitrogen, phosphorus and potassium following standard method . Analysis of different soil samples from Solapur district indicated that zinc is most common deficient in soil. The crop response to micronutrients application varies with soil type, crops and genotype, agroclimatic conditions. Identification of the micronutrient deficiency-stress tolerant varieties and exploitation of synergistic micronutrient interactions for sustainable crop production. According to an estimate, the current micronutrients application to crops may need to be doubled to meet the food demand of population of the country. The challenge of crop nutrient management is to balance production and economic optimization with environmental impacts. Successful crop production is dependent upon effective nutrient management that includes identifying nutrient deficiencies and excesses. Soil sampling and soil testing provides an opportunity to check the "soil nutrient account" and is critical for developing a nutrient management plan. Knowing the nutrient requirements and nutrient removal by a crop is important for achieving a balance of nutrient inputs and crop removal outputs. Reliable nutrient recommendations are dependent upon accurate soil tests and crop nutrient calibrations based on extensive field research.

\section{Materials and Methods}

\section{Soil sampling and testing}

Field sampling and soil testing has become an important tool for assessing soil fertility and arriving at proper fertilizer recommendations. It's also a valuable management aid for studying soil changes resulting from cropping practices and for diagnosing specific cropping problems. Soil testing provides an index for the nutrient availability in soil and is a critical step in nutrient management planning. Soil sampling technique, timing of sampling and type of analysis need to be considered for accurate results. The biggest problem in the effective use of soil testing is proper and representative sampling. Proper soil sampling will provide accurate soil test results and reliable nutrient recommendations

\section{Description of the study area}

The Solapur district is bounded by $17^{\circ} 05^{\prime}$ North latitudes to $18^{\circ} 32^{\prime}$ North latitudes and $74^{\circ} 42^{\prime}$ East of $76^{\circ} 15^{\prime}$ East longitudes. The total geographical area of Sholapur district is 14895 Sq.Km. divided into eleven tahsils. The Population is 32.4 lakhs in eleven tahsils of district (Censes 2001). It is bounded from the North by Osmanabad district and Ahmednagar district, on the North-East by Satara district and at the South \&East it has common boundary of karanataka state. Temperature is high in summer season. Rainfall varies from East to West between ranges of 200 to 600 millimeters of which about $80 \%$ is received from south west monsoon during June to September. The average number of rainy days is spread around 4 months over 60 rainy decreasing progressively to west $989.20 \mathrm{~mm}$, indicating 
relative moist eastern and dry western sectors and it is of regular nature .The annual temperature ranges from $250 \mathrm{c}$ to $270 \mathrm{c}$.The region experiences hot and mild winter with mean summer temperature of $330 \mathrm{c}$ and mean winter temperature of $21.60 \mathrm{c}$. The rivers like Bhima, Sina, Man, Nira, Bhogawati and many other smaller tributaries drain in the district. Banana, Cottan, Jawar, Sugarcan, Grain, Grapes, Bajari, Wheat, The soil of the district is mainly of Deccan Trap Volcanic origin.

\section{Analytical details of soil samples}

Soil samples $(0-15 \mathrm{~cm})$ were collected from different sites covering all villages, keeping in view the physiographic characteristic in different cross sections of the area as well as variation in soil texture. Soil samples were collected from different area of Solapur district by standard method using auger. The soil samples were dried in air and passed through a $2 \mathrm{~mm}$ mesh sieve then stored for analysis. DTPA extracts method $\mathrm{Cu}, \mathrm{Zn}, \mathrm{Fe}$, and $\mathrm{Mn}$ were determined by atomic absorption spectrophotometer. Study was designed to determine the status of micronutrients in agriculturally fertile soils of district Solapur. Represented soil samples were collected with wooden tools to avoid any contamination of the soils. Four to six pits were dug for each sample. Sample was collected at a depth $0-30 \mathrm{~cm}$. A composite sample of about $1 \mathrm{~kg}$ was taken through mixing of represented soil sample. All composite samples were dried, ground with wooden mottle and passed through $2 \mathrm{~mm}$ sieve. After sieving all the samples were packed in the polythene bags for laboratory analysis.

\section{Analysis of soil sample}

The method commonly used for determining the available micronutrient in soil sample is given by Lindsay and Norvell (1978).
Available $\mathrm{Fe}, \mathrm{Mn}, \mathrm{Cu}$ and $\mathrm{Zn}$ in soil samples were extracted with a DTPA solution (0.005M DTPA + $0.01 \mathrm{M} \mathrm{CaCl}_{2}+0.1 \mathrm{M}$ triethanolamine, $\mathrm{pH} 7.3$ as outlined by Lindsay and Norvell. The concentration of micronutrients in the extract was determined by atomic absorption spectrophotometer (ECIL, AAS-4129). The method consist of use of DTPA as an extract which has been widely accepted simultaneous extraction of micronutrient $\mathrm{Zn}$ (Zinc), $\mathrm{Cu}$ (Copper), $\mathrm{Mn}$ (Manganese) and $\mathrm{Fe}$ (Iron) in neutral and alkaline soils. This content of these micronutrients in the soil determined on an Atomic Absorption Spectrophotometer. The different physical parameters and while calcium and magnesium, carbonate, bicarbonate, chloride were estimated volumetrically, macro elements were analyzed in laboratory are $\mathrm{pH}, \mathrm{EC}, \mathrm{C}$ org, $\mathrm{P}$ and $\mathrm{K}$. The micro elements such as $\mathrm{Cu}, \mathrm{Zn}$, $\mathrm{Fe}, \mathrm{Mn}$ were estimated by Atomic Absorption Spectroscopy.

\section{Results and Discussion}

To study this, there were 2000 surface soil samples collected from growing fields of Solapur district. The soils were analyzed for physico-chemical properties and status of available micronutrients. The results shows that majority of the soil sites were alkaline in nature with medium amount of organic matter and lime content. Considering textural classes most of the sites were sandy loam. The soil $\mathrm{pH}$ ranges from 6.88 to 8.06 (average 7.56). The organic matter content ranged from 0.65 to $2.07 \%$ (average $1.18 \%$ ). Most of the soil sample shows the slightly alkaline nature and low value of $\mathrm{N}$ and $\mathrm{P}$. The potassium was medium range in almost soil. Excess of phosphorus will not have direct effect on the plant but may show visual deficiencies $\mathrm{Zn}, \mathrm{Fe}$ and $\mathrm{Mn}$, whereas, due to the excess of potassium plants will exhibit typical $\mathrm{Mg}$ and possibly $\mathrm{Ca}$ deficiency symptom due to a 
cation imbalance. The excess amount of micronutrient shows a bronzing of leaves with tiny brawn spots on the leaves. The data reveals that in location point where the soil are deficient in $\mathrm{N}, \mathrm{P}, \& \mathrm{~K}$ which requires addition of extra fertilizer and manures to make it suitable plantation and for increasing plant growth. In contrast to deficiency of micronutrients in soil may cause decline in crop yields and total productivity in future. As par the nutrient index value, soil factors such as $\mathrm{pH}, \mathrm{EC}, \mathrm{OC}$ and $\mathrm{CaCO}_{3}$ were contributed lower fertility status in relation to availability of micronutrients. Strategies involving the soil application of micronutrients by seed treatment, foliar sprays or use of organic manures can adopt to sustain an optimum yield of crop. The soils of Solapur district are neutral to alkaline in soil reaction, safe in electrical conductivity, medium in organic carbon content and calcareous in nature. According to the concept of soil nutrient index soils are deficient in Zinc and Boron while sufficient in Copper, Manganese and Iron content.

Table.1 Tahsil-wise list of census villages in Solapur district, Maharashtra, India

\begin{tabular}{|l|l|l|}
\hline Sr No & \multicolumn{1}{|c|}{ Tahsil } & \multicolumn{1}{c|}{ Total Villages } \\
\hline $\mathbf{1}$ & Akkalkot & 143 \\
\hline $\mathbf{2}$ & Barshi & 140 \\
\hline $\mathbf{3}$ & Karmala & 124 \\
\hline $\mathbf{4}$ & Madha & 118 \\
\hline $\mathbf{5}$ & Malshiras & 117 \\
\hline $\mathbf{6}$ & Mangalvedhe & 82 \\
\hline $\mathbf{7}$ & Mohol & 104 \\
\hline $\mathbf{8}$ & Pandharpur & 103 \\
\hline $\mathbf{9}$ & Sangole & 103 \\
\hline $\mathbf{1 0}$ & Solapur North & 42 \\
\hline $\mathbf{1 1}$ & Solapur South & 91 \\
\hline
\end{tabular}

Table.2 Range values of physiochemical properties of tested soil samples of district Solapur

\begin{tabular}{|l|l|l|}
\hline $\begin{array}{l}\text { Sr. } \\
\text { No }\end{array}$ & Physiochemical Properties & Range \\
\hline $\mathbf{1}$ & Soil $\mathrm{P}^{\mathrm{H}}$ & $6.88-8.06$ \\
\hline $\mathbf{2}$ & Organic Matter \% & $0.65-2.07$ \\
\hline $\mathbf{3}$ & Lime \% & $1.00-9.37$ \\
\hline $\mathbf{4}$ & Sand \% & $31.12-81.12$ \\
\hline $\mathbf{5}$ & Silt \% & $8.56-46.00$ \\
\hline $\mathbf{6}$ & Clay \% & $8.88-26.88$ \\
\hline
\end{tabular}


Table.3 Range and average values of micronutrients of tested soil samples of district Solapur

Soil nutrient condition for wheat in Mohol Tehsil

\begin{tabular}{|l|c|c|c|}
\hline Nutrients & $\begin{array}{c}\text { An Ideal Nutrient } \\
\text { Condition For } \\
\text { Wheat }\end{array}$ & \multicolumn{2}{|c|}{$\begin{array}{c}\text { Actual Nutrient } \\
\text { Condition }\end{array}$} \\
\cline { 3 - 4 } & Irrigated & $\begin{array}{c}\text { Non- } \\
\text { irrigated }\end{array}$ \\
\hline Ph & $6.5-7.8$ & 7.6 & $\mathbf{7 . 9 6}$ \\
\hline Nitrogen & 128 & 326.14 & $\mathbf{1 7 5 . 6 2}$ \\
\hline Phosphorus & 46 & 47.04 & $\mathbf{3 8 . 5 1}$ \\
\hline Potassium (K) & 219 & 680 & $\mathbf{6 1 6}$ \\
\hline Calcium & 27 & 75 & $\mathbf{3 5}$ \\
\hline Magnesium & 19 & 46 & $\mathbf{2 3}$ \\
\hline Sulphur & 22 & 37 & $\mathbf{1 5 . 6 2}$ \\
\hline Iron (Fe) & 1.8 & 2.74 & $\mathbf{3 . 2 3}$ \\
\hline Zinc & 0.5 & 2.87 & $\mathbf{0 . 4 5}$ \\
\hline Manganese & 0.5 & 4.81 & $\mathbf{5 . 0 3}$ \\
\hline Copper $(\mathbf{C u})$ & $\mathbf{0 . 1 5}$ & $\mathbf{1 . 8 7}$ & $\mathbf{2 . 3 8}$ \\
\hline
\end{tabular}

Source: Compiled by Researcher

Table.4 Soil nutrient condition for wheat in Pandharpur Tehsil

\begin{tabular}{|l|c|c|c|}
\hline Nutrients & $\begin{array}{c}\text { An Ideal Nutrient } \\
\text { Condition For } \\
\text { Wheat }\end{array}$ & \multicolumn{2}{|c|}{$\begin{array}{c}\text { Actual Nutrient } \\
\text { Condition }\end{array}$} \\
\cline { 3 - 4 } & Irrigated & $\begin{array}{c}\text { Non- } \\
\text { irrigated }\end{array}$ \\
\hline pH & $6.5-7.8$ & 7.88 & $\mathbf{7 . 8 5}$ \\
\hline Nitrogen & 128 & 225.79 & $\mathbf{1 7 5 . 6 2}$ \\
\hline Phosphorus & 46 & 31.36 & $\mathbf{2 6 . 7 2}$ \\
\hline Potassium & 219 & 952 & $\mathbf{7 8 4}$ \\
(K) & & & \\
\hline Calcium & 27 & 65.9 & $\mathbf{5 7 . 7}$ \\
\hline Magnesium & 19 & 37.2 & $\mathbf{3 3 . 4}$ \\
\hline Sulphur & 22 & 36.15 & $\mathbf{1 6 . 8 5}$ \\
\hline Iron (Fe) & 1.8 & 2.70 & $\mathbf{2 . 6 3}$ \\
\hline Zinc & 0.5 & 1.48 & $\mathbf{1 . 2 1}$ \\
\hline Manganese & 0.5 & 2.20 & $\mathbf{1 . 9 9}$ \\
\hline Copper $(\mathbf{C u})$ & $\mathbf{0 . 1 5}$ & $\mathbf{2 . 7 7}$ & $\mathbf{2 . 2 0}$ \\
\hline
\end{tabular}

Source: Compiled by Researcher 
Table.5 Soil nutrient condition for wheat in Mangalwedha Tehsil

\begin{tabular}{|l|c|c|c|}
\hline Nutrients & $\begin{array}{c}\text { An Ideal Nutrient } \\
\text { Condition For } \\
\text { Wheat }\end{array}$ & \multicolumn{2}{|c|}{$\begin{array}{c}\text { Actual Nutrient } \\
\text { Condition }\end{array}$} \\
\cline { 3 - 4 } & Irrigated & $\begin{array}{c}\text { Non- } \\
\text { irrigated }\end{array}$ \\
\hline pH & $6.5-7.8$ & 7.66 & $\mathbf{7 . 1 1}$ \\
\hline Nitrogen & 128 & 200.7 & $\mathbf{2 0 0 . 7}$ \\
\hline Phosphorus & 46 & 24.42 & $\mathbf{1 7 . 5 6}$ \\
\hline Potassium & 219 & 504 & $\mathbf{3 6 8}$ \\
\hline (K) & & & \\
\hline Calcium & 27 & 60 & $\mathbf{4 5}$ \\
\hline Magnesium & 19 & 87 & $\mathbf{7 4}$ \\
\hline Sulphur & 22 & 43.00 & $\mathbf{6 2 . 8 4}$ \\
\hline Iron (Fe) & 1.8 & 4.13 & $\mathbf{3 . 8 1}$ \\
\hline Zinc & 0.5 & 0.90 & $\mathbf{1 . 1 2}$ \\
\hline Manganese & 0.5 & 3.59 & $\mathbf{2 . 3 4}$ \\
\hline Copper $(\mathbf{C u})$ & $\mathbf{0 . 1 5}$ & $\mathbf{1 . 9 3}$ & $\mathbf{3 . 2 8}$ \\
\hline
\end{tabular}

Source: Compiled by Researcher

Table.6 Soil Nutrient Condition for Wheat in Akkalkot Tehsil

\begin{tabular}{|l|c|c|c|}
\hline Nutrients & $\begin{array}{c}\text { An Ideal Nutrient } \\
\text { Condition For } \\
\text { Wheat }\end{array}$ & \multicolumn{2}{|c|}{$\begin{array}{c}\text { Actual Nutrient } \\
\text { Condition }\end{array}$} \\
\cline { 3 - 4 } & & Irrigated & $\begin{array}{c}\text { Non- } \\
\text { irrigated }\end{array}$ \\
\hline pH & $6.5-7.8$ & 8.18 & $\mathbf{7 . 7 9}$ \\
\hline Nitrogen & 128 & 200.7 & $\mathbf{2 0 0 . 7}$ \\
\hline Phosphorus & 46 & 27.1 & $\mathbf{1 3 . 3}$ \\
\hline Potassium & 219 & 504 & $\mathbf{5 0 4}$ \\
\hline (K) & & & \\
\hline Calcium & 27 & 80.35 & $\mathbf{6 5 . 7 7}$ \\
\hline Magnesium & 19 & 73 & $\mathbf{7 8}$ \\
\hline Sulphur & 22 & 41.07 & $\mathbf{3 8 . 4 7}$ \\
\hline Iron $($ Fe) & 1.8 & 3.64 & $\mathbf{4 . 0 0}$ \\
\hline Zinc & 0.5 & 0.90 & $\mathbf{1 . 2 1}$ \\
\hline Manganese & 0.5 & 3.10 & $\mathbf{3 . 4 6}$ \\
\hline Copper $(\mathbf{C u})$ & $\mathbf{0 . 1 5}$ & $\mathbf{3 . 2 7}$ & $\mathbf{2 . 6 5}$ \\
\hline
\end{tabular}

Source: Compiled by Researcher 
Table.7 Soil nutrient condition for wheat in Madha Tehsil

\begin{tabular}{|l|c|c|c|}
\hline Nutrients & $\begin{array}{c}\text { An Ideal Nutrient } \\
\text { Condition For } \\
\text { Wheat }\end{array}$ & \multicolumn{2}{|c|}{$\begin{array}{c}\text { Actual Nutrient } \\
\text { Condition }\end{array}$} \\
\cline { 3 - 4 } & & \multicolumn{2}{|c|}{$\begin{array}{c}\text { Irrigated } \\
\text { irrigated }\end{array}$} \\
\hline pH & $6.5-7.8$ & 7.63 & $\mathbf{7 . 9 5}$ \\
\hline Nitrogen & 128 & 200.7 & $\mathbf{1 2 5 . 4 4}$ \\
\hline Phosphorus & 46 & 16.74 & $\mathbf{1 4 . 4 8}$ \\
\hline Potassium & 219 & 448 & $\mathbf{5 6 8}$ \\
(K) & 27 & & \\
\hline Calcium & 19 & 63.46 & $\mathbf{5 6 . 3 2}$ \\
\hline Magnesium & 22 & 48.82 & $\mathbf{4 4 . 5 3}$ \\
\hline Sulphur & 1.8 & 44.92 & $\mathbf{4 5 . 4 8}$ \\
\hline Iron (Fe) & 0.5 & 5.17 & $\mathbf{3 . 4 6}$ \\
\hline Zinc & 0.5 & 0.58 & $\mathbf{0 . 4 0}$ \\
\hline Manganese & $\mathbf{0 . 1 5}$ & 3.59 & $\mathbf{3 . 2 3}$ \\
\hline Copper $($ Cu) & & $\mathbf{2 . 1 5}$ & $\mathbf{2 . 1 1}$ \\
\hline
\end{tabular}

Source: Compiled by Researcher

Table.8 Soil nutrient condition for wheat in South Solapur Tehsil

\begin{tabular}{|l|c|c|c|}
\hline Nutrients & $\begin{array}{c}\text { An Ideal Nutrient } \\
\text { Condition For } \\
\text { Wheat }\end{array}$ & \multicolumn{2}{|c|}{$\begin{array}{c}\text { Actual Nutrient } \\
\text { Condition }\end{array}$} \\
\cline { 3 - 4 } & & Irrigated & $\begin{array}{c}\text { Non- } \\
\text { irrigated }\end{array}$ \\
\hline pH & $6.5-7.8$ & 7.87 & $\mathbf{7 . 8 1}$ \\
\hline Nitrogen & 128 & 225.79 & $\mathbf{2 0 0 . 7}$ \\
\hline Phosphorus & 46 & 25.46 & $\mathbf{2 1 . 9 7}$ \\
\hline Potassium & 219 & 752 & $\mathbf{6 9 6}$ \\
(K) & 27 & & \\
\hline Calcium & 19 & 48.46 & $\mathbf{5 5 . 2 6}$ \\
\hline Magnesium & 22 & 45.23 & $\mathbf{4 7 . 9 2}$ \\
\hline Sulphur & 1.8 & 3.84 & $\mathbf{3 . 0 2}$ \\
\hline Iron (Fe) & 0.5 & 0.81 & $\mathbf{0 . 7 6}$ \\
\hline Zinc & 0.5 & 3.73 & $\mathbf{2 . 7 4}$ \\
\hline Manganese & $\mathbf{0 . 1 5}$ & $\mathbf{3 . 6 5}$ & $\mathbf{2 . 8 3}$ \\
\hline Copper (Cu) & Source: Compiled by Researcher & \\
\hline
\end{tabular}


Table.9 Soil nutrient condition for wheat in North Solapur Tehsil

\begin{tabular}{|l|l|l|l|}
\hline Nutrients & $\begin{array}{l}\text { An Ideal Nutrient } \\
\text { Condition For Wheat }\end{array}$ & $\begin{array}{l}\text { Actual Nutrient } \\
\text { Condition }\end{array}$ \\
\cline { 4 - 4 } & & Irrigated & $\begin{array}{l}\text { Non- } \\
\text { irrigated }\end{array}$ \\
\hline pH & $6.5-7.8$ & 7.48 & $\mathbf{7 . 8}$ \\
\hline Nitrogen & 128 & 250.88 & $\mathbf{2 0 0 . 7}$ \\
\hline Phosphorus & 46 & 19.79 & $\mathbf{1 8 . 9 6}$ \\
\hline $\begin{array}{l}\text { Potassium } \\
\text { (K) }\end{array}$ & 219 & 224 & $\mathbf{1 5 2}$ \\
\hline Calcium & 27 & 63.12 & $\mathbf{5 5 . 7 8}$ \\
\hline Magnesium & 19 & 37.19 & $\mathbf{3 4 . 2 8}$ \\
\hline Sulphur & 22 & 36.15 & $\mathbf{3 9 . 3 3}$ \\
\hline Iron $($ Fe) & 1.8 & 3.81 & $\mathbf{4 . 0 0}$ \\
\hline Zinc & 0.5 & 1.35 & $\mathbf{0 . 4 0}$ \\
\hline Manganese & 0.5 & 3.05 & $\mathbf{3 . 2 1}$ \\
\hline Copper $($ Cu) & $\mathbf{0 . 1 5}$ & $\mathbf{2 . 8 4}$ & $\mathbf{3 . 2 8}$ \\
\hline
\end{tabular}

Source: Compiled by Researcher

Table.10 Soil Nutrient Condition for Wheat in Karmala Tehsil

\begin{tabular}{|c|c|c|c|}
\hline \multirow[t]{2}{*}{ Nutrients } & \multirow[t]{2}{*}{$\begin{array}{l}\text { An Ideal Nutrient } \\
\text { Condition For Wheat }\end{array}$} & \multicolumn{2}{|c|}{$\begin{array}{l}\text { Actual Nutrient } \\
\text { Condition }\end{array}$} \\
\hline & & Irrigated & $\begin{array}{l}\text { Non- } \\
\text { irrigated }\end{array}$ \\
\hline pH & $6.5-7.8$ & 7.17 & 7.74 \\
\hline Nitrogen & 128 & 225.79 & 175.62 \\
\hline Phosphorus & 46 & 23.07 & 16.05 \\
\hline $\begin{array}{l}\text { Potassium } \\
\text { (K) }\end{array}$ & 219 & 336 & 672 \\
\hline Calcium & 27 & 63.56 & 60.32 \\
\hline Magnesium & 19 & 42.61 & 33.54 \\
\hline Sulphur & 22 & 49.54 & 42.84 \\
\hline Iron $(\mathbf{F e})$ & 1.8 & 4.31 & 2.70 \\
\hline Zinc & 0.5 & 0.58 & 0.45 \\
\hline Manganese & 0.5 & 3.20 & 2.96 \\
\hline Copper (Cu) & 0.15 & 3.22 & 3.05 \\
\hline
\end{tabular}

Source: Compiled by Researcher 
Table.11 Soil nutrient condition for wheat in Sangola Tehsil

\begin{tabular}{|l|c|c|c|}
\hline Nutrients & $\begin{array}{c}\text { An Ideal Nutrient } \\
\text { Condition For Wheat }\end{array}$ & \multicolumn{2}{|c|}{$\begin{array}{c}\text { Actual Nutrient } \\
\text { Condition }\end{array}$} \\
\cline { 3 - 4 } & & Irrigated & $\begin{array}{c}\text { Non- } \\
\text { irrigated }\end{array}$ \\
\hline pH & $6.5-7.8$ & 8.3 & $\mathbf{7 . 7 9}$ \\
\hline Nitrogen & 128 & 200.35 & $\mathbf{2 7 5 . 9 7}$ \\
\hline Phosphorus & 46 & 36.05 & $\mathbf{4 2 . 3 4}$ \\
\hline $\begin{array}{l}\text { Potassium } \\
\text { (K) }\end{array}$ & 219 & 480 & $\mathbf{4 4 8}$ \\
\hline Calcium & 27 & 57.21 & $\mathbf{5 1 . 7 0}$ \\
\hline Magnesium & 19 & 37.65 & $\mathbf{3 1 . 5 2}$ \\
\hline Sulphur & 22 & 51.77 & $\mathbf{4 8 . 5 4}$ \\
\hline Iron $($ Fe) & 1.8 & 3.47 & $\mathbf{2 . 0 7}$ \\
\hline Zinc & 0.5 & 0.85 & $\mathbf{1 . 3 0}$ \\
\hline Manganese & 0.5 & 3.48 & $\mathbf{2 . 7 7}$ \\
\hline Copper $(\mathbf{C u})$ & $\mathbf{0 . 1 5}$ & $\mathbf{3 . 2 9}$ & $\mathbf{2 . 8 0}$ \\
\hline
\end{tabular}

Source: Compiled by Researcher

Table.12 Soil nutrient condition for wheat in Barshi Tehsil

\begin{tabular}{|l|c|c|c|}
\hline Nutrients & $\begin{array}{c}\text { An Ideal Nutrient } \\
\text { Condition For } \\
\text { Wheat }\end{array}$ & \multicolumn{2}{|c|}{$\begin{array}{c}\text { Actual Nutrient } \\
\text { Condition }\end{array}$} \\
\cline { 3 - 4 } & & Irrigated & Non-irrigated \\
\hline pH & $6.5-7.8$ & 7.6 & $\mathbf{7 . 7 5}$ \\
\hline Nitrogen & 128 & 150.53 & $\mathbf{1 7 5 . 6 2}$ \\
\hline Phosphorus & 46 & 55.9 & $\mathbf{5 8 . 0 2}$ \\
\hline Potassium & 219 & 728 & $\mathbf{4 4 8}$ \\
(K) & & & \\
\hline Calcium & 27 & 45.56 & $\mathbf{3 5 . 3 6}$ \\
\hline Magnesium & 19 & 36.46 & $\mathbf{3 1 . 8 3}$ \\
\hline Sulphur & 22 & 44.69 & $\mathbf{2 2 . 4 6}$ \\
\hline Iron (Fe) & 1.8 & 2.70 & $\mathbf{3 . 8 2}$ \\
\hline Zinc & 0.5 & 0.49 & $\mathbf{0 . 5 4}$ \\
\hline Manganese & 0.5 & 2.16 & $\mathbf{2 . 4 3}$ \\
\hline Copper (Cu) & $\mathbf{0 . 1 5}$ & $\mathbf{3 . 5 0}$ & $\mathbf{3 . 0 1}$ \\
\hline & Source: Compiled by Researcher & \\
\hline
\end{tabular}


Table.13 Soil nutrient condition for wheat in Malshiras Tehsil

\begin{tabular}{|l|c|c|c|}
\hline Nutrients & $\begin{array}{c}\text { An Ideal Nutrient } \\
\text { Condition For } \\
\text { Wheat }\end{array}$ & \multicolumn{2}{|c|}{$\begin{array}{c}\text { Actual Nutrient } \\
\text { Condition }\end{array}$} \\
\cline { 3 - 4 } & & Irrigated & Non-irrigated \\
\hline pH & $6.5-7.8$ & 8.00 & $\mathbf{7 . 9}$ \\
\hline Nitrogen & 128 & 150.53 & $\mathbf{1 7 5 . 6 2}$ \\
\hline Phosphorus & 46 & 70.4 & $\mathbf{6 6 . 4 6}$ \\
\hline Potassium & 219 & 616 & $\mathbf{5 8 4}$ \\
\hline (K) & & & \\
\hline Calcium & 27 & 48.62 & $\mathbf{4 1 . 6 0}$ \\
\hline Magnesium & 19 & 49.21 & $\mathbf{3 4 . 8 6}$ \\
\hline Sulphur & 22 & 48.08 & $\mathbf{3 9 . 8 4}$ \\
\hline Iron $($ Fe) & 1.8 & 2.68 & $\mathbf{1 . 8 9}$ \\
\hline Zinc & 0.5 & 1.62 & $\mathbf{1 . 6 1}$ \\
\hline Manganese & 0.5 & 2.61 & $\mathbf{2 . 0 0}$ \\
\hline Copper $(\mathbf{C u})$ & $\mathbf{0 . 1 5}$ & $\mathbf{1 . 5 9}$ & $\mathbf{1 . 0 5}$ \\
\hline
\end{tabular}

Source: Compiled by Researcher

Deficiency of micronutrients in soil may cause decline in crop yields and total productivity in future. As par the nutrient index value, soil factors such as $\mathrm{pH}, \mathrm{EC}, \mathrm{OC}$ and $\mathrm{CaCO}_{3}$ were contributed lower fertility status in relation to availability of micronutrients. Strategies involving the soil application of micronutrients by seed treatment, foliar sprays or use of organic manures can adopt to sustain an optimum yield of crop. The soils of Solapur district are neutral to alkaline in soil reaction, safe in electrical conductivity, medium in organic carbon content and calcareous in nature. According to the concept of soil nutrient index soils are deficient in Zinc, Iron, and Boron while sufficient in Copper and Manganese content.

In conclusion, proper nutrition is essential for satisfactory crop growth and production and use of soil tests can help to determine the status of plant available nutrients to develop fertilizer recommendations to achieve optimum crop production. The profit potential for farmers depends on producing enough crops per acre to keep production costs below the selling price. Efficient application of the correct types and amounts of fertilizers and manure for the supply of the nutrients is an important part of achieving profitable yields and minimizing environmental impacts. More importantly, these techniques are used to evaluate soil fertility and determine whether applied fertilizers are sufficient to ensure satisfactory crop growth. Through extensive experimentation and refinement of these methodologies, fertilizer recommendations for specific crops have been developed.

\section{References}

1. Ajit Kumar, K., Singh, K. and Singh, R.N. (2009) Available nutrients and response of lentil (Lense esculenta) to boron application in rainfed uplands soils of Ranchi. Journal of the Indian Society of Soil Science 57(2), 219-222.

2. Bayala, J., Balesdent, J., Marol, C., Zapata, F., Teklehaimanot, Z. and Ouedraogo, 
S.O. (2007). Relative contribution of trees and crops to soil organic carbon content in a park land system in Burkina Faso. Advances in Integrated soil fertility management in Sub-Saharan Africa: Challenges and opportunities, 161-169.

3. Datta, M. and Ram, M. 1989. Status of micronutrients in some soil series of Tripura. Journal of the Indian Society of Soil Science, 41, 776-777.

4. Katyal, J.C. and Rattan, R.K. 2003. Secondary and micronutrients research gaps and future needs. Fertilizer News, 48,9-14.

5. Lindsay, N.L. and Norvell, W.A. 1978. Development of DTPA soil test forzinc, iron, manganese and copper.Soil Science Society of America, 42,421428.

6. Pal, S., Datta, S. P., Rattan, R. K. and Singh, A.K. (2000) Diagnosis and Amelioration of Iron Deficiency under Aerobic Rice.Journal of Plant Nutrition 31(5), 919-940.

7. Paramasivam, P. and Gopalswamy, A. 1994. Distribution of micronutrients in Lower Bhavani Project (LBP) command area soil profiles. Madras Agricultural Journal, 81, 545-547.

8. Ponnamperuma, F.N. 1972. The chemistry of submerged soils. Advances in Agronomy, 24,29-96.

9. Rattan, R.K., Patel K.P., Manjaiah K.M. and Datta S.P. 2009. Micronutrients in soil, plant, animal and human health.Journal of the Indian Society of Soil Science, 47(4), 546- 558.

1O. Rego, T.J., Sahrawat, K.L. Wani, S.P. Pardhasaradhi, G. 2007. Widespread deficiencies of sulphur, boron and zinc in dryland soils of the Indian semi arid tropical soils: on farm crop responses. Journal of Plant Nutrition 30, 15691583.

11. Sharma, J.C. and Chaudhary, S.K. 2007.
Vertical distribution of micronutrient cations in relation to soil characteristics in lower Shiwaliks of Solan district in North-West Himalayas. Journal of the Indian Society of Soil Science, 55, 4044.

12. Sharma, R.C., Mandal, A.K. and Ranbir Singh. (2011) Delineation and Characterization of Waterlogged and Salt-affected Soils in Gandak Command Area of Bihar for Reclamation and Management. Journal of the Indian Society of Soil Science 59(4), 315-320.

13. Singh, K. 2009. The critical zinc deficiency levels in Indian soils and cereal crops. In: Proc. of the International Plant Nutritional Colloquium. XVI. Dept. of Plant Sciences, UC Davis.

14. Somasundaram, J., Singh, R. K., Paraldiyal, A. R. and Prasad, S. N. 2009. Micronutrient status of soils under different land use systems in Chambal ravines. Journal of the Indian Society of Soil Science, 57(3), 307-312.

15. Venkatesh, M. S., Majumdar, B., Kumar, K. and Patiram, 2003. Status of micronutrient cations under various land use systems of Meghalaya. Journal of Indian Society of Soil Science, 51, 6064.

16 .Dhamak A. L. and Meshram N.A.,2014. Assessment of Micronitrients Indices in soils of Ambajogai Tahsil of Beed District under semiarid Agro ecological Region (Maharashtra), journal of research in agriculture and animal science volume 2, 40-43.

17. S. Ayoub, B. A. McGaw, C. A. Shand and A. J. Mid- Wood, 2003 Phytoavailability of $\mathrm{Cd}$ and $\mathrm{Zn}$ in Soil Estimated by Stable isotope Exchange and Chemical Extraction, Crops and Soil, , 252, No. 2, 291-300.

18. E.O. McLean and M. E. Watson,1985, Soil Measurements of Crops-Available 
Potassium in Agriculture, Soil Science Society of America, Madison, Pp. 227308.

19. Durand, N. Bellon and B. Jaillard, 2001,Determining the Net Flux of Charge Released by Maize Roots by Directly Measuring Variations of the Alkalinity in the Nutrient Solution",
Crops and Soil, 229, 305-318.

20.M. J. McLaughlin, P. A. Lancaster, P. W. G. Sale, N. C. Uren and K. I. Peverill, 1993, Use of Cation/Anion Exchange Membranes for Multi-Element Testing of Acidic Soils, Crops and Soil, 155156, No. 1. 223-226.

\section{How to cite this article:}

Reshma D. Mulani, Vijay B. Upadhye and Bhosale, B. D. 2020. The Micronutrients Status and Physio-Chemical Properties of Geo Referenced Soils of Solapur District in Maharashtra, India. Int.J.Curr.Microbiol.App.Sci. 9(01): 953-964. doi: https://doi.org/10.20546/ijcmas.2020.901.107 